\title{
Psoriasis: Ustekinumab and Other Biologics in the Pipeline
}

\author{
Noori Kim • Alice B. Gottlieb
}

Published online: 5 July 2012

(C) Springer Science+Business Media, LLC 2012

\begin{abstract}
The improved understanding of the complex immunology and pathogenesis of psoriasis and psoriatic arthritis has established the therapeutic utility of targeted biologic therapies against the pathogenic $\mathrm{T}$ cells and the inflammatory cytokines. Particular interest in the interleukin (IL)-23/ $\mathrm{T}$ helper (Th)17 pathway has led to the development of ustekinumab, which is now approved and widely marketed for the treatment of psoriasis, as well as various investigational biologic agents in current clinical trials. Lack of or improper treatment of psoriasis and psoriatic arthritis can inevitably result in considerable morbidity and quality of life issues for affected patients, emphasizing the continued need for drug research and development to achieve optimal management.
\end{abstract}

Keywords Dermatopharmacology · Therapy · Psoriasis · Psoriatic arthritis · Comorbidities · Biologics · Immunology · Pathogenesis · Cytokines · Tcells $\cdot$ IL-23/Th17 pathway · IL$12 \cdot$ IL-22 $\cdot$ IL-23 $\cdot$ IL-17 $\cdot$ Tumor necrosis factor-alpha . TNF- $\alpha$ - Ustekinumab · Briakinumab · IL-23 inhibitors . TNF inhibitors $\cdot$ T-cell modulators

\section{Introduction}

Psoriasis is a chronic inflammatory skin condition that affects approximately $2 \%$ of the US population [1]. Of this population, an estimated $6 \%$ to $39 \%$ have associated joint disease, which is an inflammatory arthritis that can be progressively destructive and can pose significant limitations on the functional capacity and quality of life of a patient [2-4]. The mounting evidence supporting psoriasis as a

N. Kim $(\bowtie) \cdot$ A. B. Gottlieb

Tufts Medical Center, Department of Dermatology, 800 Washington St., Box 114, Boston, MA 02111, USA

e-mail: nkim@tuftsmedicalcenter.org systemic disease - including conditions that pose considerable cardiovascular disease risks, such as metabolic syndrome, obesity, hypertension, hyperlipidemia, and diabetes, as well as psychiatric disorders - further justifies the use of systemic therapies [5-8]. The traditional systemic therapies, such as acitretin, methotrexate, and cyclosporine, are still used for the treatment of psoriasis; however, the challenges with long-term management, particularly with the concern for potential serious associated toxicities with these medications, have made biologic therapies an attractive option [9]. In fact, the efficacy of various biologic therapies in psoriasis has been shown in numerous clinical studies, and, importantly, associated with an improved quality of life for the patients $[10,11]$. As more detailed information about the complex immunopathology of psoriasis is uncovered, the need for developing targeted therapies to improve upon the efficacy, safety, and durability of available treatment options becomes essential.

\section{Background: The Interleukin (IL)-23/T Helper (Th)17 Pathway}

Although psoriasis is already known as a disease of T-cell mediated chronic inflammation, the increasingly documented evidence that the pathogenesis of psoriasis is through a particular subset of CD4+T helper cells, Th17, has ultimately led to a focus on the development of a new class of biologic therapies $[12,13]$. Notably, the Th17 cell lineage is a novel and separate entity from the different arms of cellular immunity, such as Th1 and Th2 cells, that is responsible for the production of cytokines involved in skin inflammation, such as IL-17A, IL-17F, IL-22 [14, 15]. As part of the complex pro-inflammatory cascade in psoriasis, transforming growth factor-beta 1 (TGF- $\beta 1$ ) and IL-6 have been shown to be essential in the differentiation of naïve $T$ 
cells into Th17 cells [16-18]. TGF- $\beta 1$, in itself, is elevated in psoriasis and released by keratinocytes upon stress from any injury or infection $[19,20]$. The mRNA and protein levels for IL- 6 also have been noted to be elevated in psoriatic plaques [21]. IL-23, then, subsequently may provide a stimulus for the proliferation of the Th17 cells [22, 23]. Dendritic cells secrete IL-23 - along with IL-12, another key cytokine for Th1 differentiation-but IL-23 also can be produced by keratinocytes and non-dendritic, antigenpresenting cells [24-26]. IL-23, a heterodimeric cytokine in the IL-12 family, is composed of the p19 and p40 subunits that can then bind to the receptor made up of IL-12R $\beta 1$ and IL-23R [27]. IL-12, another heterodimeric cytokine, not only shares the $\mathrm{p} 40$ subunit with IL-23 but consists of the p35 subunit [28]. In fact, the pivotal role that the IL-23/ Th17 axis plays in psoriasis pathogenesis is reinforced by evidence that the mRNA levels of the subunit p19-unique to IL-23 - were elevated in psoriasis lesional skin compared to non-lesional skin, whereas the levels for $\mathrm{p} 35$ - a subunit distinct to IL-12 - were not [29-31]. Importantly, the levels of IL-23 decreased in correlation to skin improvement and efficacy of various therapies-including phototherapy, cyclosporin A, and tumor necrosis factor-alpha (TNF- $\alpha$ ) inhibitors-further crediting the role of IL-23 in psoriasis pathology and its utility as a therapeutic target [32-34]. Moreover, specific nucleotide polymorphisms for the IL23 receptor gene have been associated with psoriasis in large-scale genetic association studies [35-37]. Ultimately, targeting the IL-23/Th17 pathway for the treatment of psoriasis initially led to the development of two biologics, CNTO-1275/ustekinumab and ABT-874/briakinumab.

\section{Ustekinumab, Briakinumab, and Other IL-23 Inhibitors}

Ustekinumab is a human monoclonal immunoglobulin $\mathrm{G}$ (IgG) antibody that effectively inhibits IL-12 and IL-23 by binding to the shared $\mathrm{p} 40$ subunit, and thereby inhibiting the cytokines from binding to the receptors [38]. It is currently marketed in the United States and worldwide for the treatment of moderate-to-severe psoriasis. Phase I and II studies have already established the efficacy of ustekinumab at various doses against placebo by week 12 , as measured by a $75 \%$ reduction in the Psoriasis Area and Severity Index score (PASI 75) [39-41]. There were two notable large-scale, phase III, double-blind, placebo-controlled trials with ustekinumab, known as PHOENIX 1 and PHOENIX 2, in which subjects were dosed at either $45 \mathrm{mg}$ or $90 \mathrm{mg}$ at weeks 0,4 , and then every 12 weeks for the treatment of moderate-to-severe plaque psoriasis [42•,43•]. The PHOENIX 1 trial illustrated that a significantly higher percentage of patients achieved the PASI 75 response by week 12 for both the $45 \mathrm{mg}$ and $90 \mathrm{mg}$ ustekinumab doses compared to placebo, and the response was sustained through week 76 for those patients who remained on a maintenance dose of ustekinumab against the group who had the drug withdrawn [42•]. The PHOENIX 2 study further validated the results of ustekinumab's efficacy, as more patients who received either 45-mg or 90-mg doses of ustekinumab reached at least a PASI 75 score by week 12 as compared to the placebo group ( $66.7 \%$ and $75.7 \%$ vs $3.7 \%$, respectively; $p<0.0001$ ) [43•].

Adjunct to the objective improvements in the PASI scores, the scores of the Dermatology Life Quality Index (DLQI), which reflects the quality of life and indirect costs for each individual, also improved for groups receiving ustekinumab compared to those on placebo [42•, 43•]. Furthermore, the ACCEPT trial, a large-scale comparator study between two doses of ustekinumab, $45 \mathrm{mg}$ and $90 \mathrm{mg}$, and etanercept at $50 \mathrm{mg}$ twice weekly, showed that more patients on ustekinumab had a PASI 75 score at week 12 compared to those on etanercept [44•].

Ustekinumab has been used in patients with psoriatic arthritis as well, and phase II results from 2009 showed that a greater proportion of patients receiving either $63 \mathrm{mg}$ or $90 \mathrm{mg}$ of ustekinumab achieved $20 \%$ improvements in their joint exam scores (American College of Rheumatology criteria for $20 \%$ improvement [ACR 20]) by week 12 compared to those on placebo ( $42 \%$ vs $14 \% ; p=0.0002$ ) [45•]. Consequently, phase III clinical trials evaluating the efficacy of ustekinumab for psoriasis arthritis are currently taking place [46]. In addition, a recent open-label trial evaluating the efficacy of ustekinumab in palmoplantar psoriasis provided evidence that the higher dosing of $90 \mathrm{mg}$ may have utility in treating this psoriasis variant that is known to be resistant to many other forms of treatment [47•].

Briakinumab is the recombinant, fully human monoclonal IgG1 antibody also against the p40 subunit that carries out its therapeutic function by binding soluble IL-12 and IL23 [48, 49]. The therapeutic efficacy of briakinumab was clear across five different doses against placebo for patients with moderate-to-severe plaque psoriasis in a phase II study (63\%-93\% vs $3 \% ; p<0.001$ ) [48]. Subsequent phase III trials continued to show impressive results, with PASI 75 scores achieved for those on briakinumab compared to placebo as well as established treatments such as etanercept and methotrexate and with therapeutic efficacies maintained through week 48 in the open-label extension studies [50, $51 \bullet, 52 \bullet$. The safety profile of briakinumab did include an increased number of major adverse cardiovascular events in the treatment group compared to the placebo group. However, despite the marked therapeutic responses seen in the briakinumab-treated groups, the drug's application for approval was withdrawn in 2011, halting further development for briakinumab at this time [53].

Other IL-23 inhibitors are currently in development, including an antibody that specifically targets the p19 subunit 
of IL-23, which has been demonstrated to decrease the mRNA levels of Th17 cytokines in certain mouse models [54]. The hypothesis is that, by directly inhibiting the subunit unique to IL-23, IL-12 and Th1 driven cell-mediated immunity will be preserved, ameliorating the potential infection and cancer risks $[55,56]$. Of note, there is one phase II study evaluating the efficacy of an anti-p19 antibody for the treatment of moderate-to-severe plaque psoriasis, $\mathrm{SCH}$ 900222 (Merck) [46].

\section{Targeting Th17 Cytokines: IL-17 and IL-22}

The importance of the IL-23/Th17 axis in the immunopathogenesis of psoriasis has been highlighted by the efficacy of anti-IL-23 biologic agents for the treatment of psoriasis and has led to the consideration of other downstream components of the pathway as therapeutic targets. In particular, IL17, one of the effector cytokines of Th17 cells, is a homodimeric cytokine that is secreted by memory $\mathrm{T}$ cells and natural killer cells, and involved in activating other key signaling pathways, such as nuclear factor- $\mathrm{kB}$ and mitogen-activated protein kinase cascades [57, 58]. IL-17 may support neutrophil recruitment in psoriasis lesions by stimulating keratinocytes to produce CXC chemokines that attract neutrophils and by inhibiting neutrophil apoptosis in inflamed tissues [59-61]. A positive feedback loop for chronic inflammation is maintained in psoriasis by IL-17. IL-17 not only reinforces the effects of TNF- $\alpha$ but induces IL-6 secretion, which directly influences Th17 differentiation [62, 63]. Correspondingly, the gene expression and mRNA levels of IL-17 were, indeed, higher in psoriatic skin compared to noninvolved skin $[29,54]$.

There are several ongoing clinical trials evaluating the efficacy and safety of anti-IL-17 biologic agents for the treatment of psoriasis. Recently, encouraging evidence from two phase II studies evaluating the efficacy and utility of biologic agents against IL-17 and its receptor was published. Brodalumab (AMG 827) is a fully human monoclonal IgG2 antibody against the IL-17 receptor [64, 65]. For the phase II trial, almost 200 patients with moderate-to-severe plaque psoriasis were randomized to receive either biweekly dosing of brodalumab at $70 \mathrm{mg}, 140 \mathrm{mg}$, or $210 \mathrm{mg}$; monthly dosing of brodalumab at $280 \mathrm{mg}$; or placebo. By the end of 12 weeks, a significant proportion of patients achieved improvement in their PASI scores by $75 \%$ (PASI 75) and $90 \%$ (PASI 90 ) for the 140 -mg dose-group (77 \% and $72 \%$, respectively) and the 210-mg dose group ( $82 \%$ and $75 \%$, respectively) compared to placebo $(0 \% ; p<0.001)$ [66 6 . The second phase II trial was a double-blind, placebocontrolled study of four different monthly doses $(10 \mathrm{mg}$, $25 \mathrm{mg}, 75 \mathrm{mg}$, or $150 \mathrm{mg}$ ) of ixekizumab (LY2439821), a humanized monoclonal IgG4 antibody against IL-17 [67•].
For all except the lowest dose, more patients on treatment achieved PASI 75 scores $(76.7 \%-82.1 \%$ vs. $7.7 \%$; $p<$ $0.001)$ and PASI 90 scores $(50 \%-71.4 \%$ vs $0 \% ; p<0.001)$ compared to those on placebo by week 12 , again conferring the efficacy of using IL-17 as a therapeutic target [67•]. Another notable upcoming biologic agent against IL-17 in development includes secukinumab (AIN457), a fully human monoclonal IgG1 antibody to IL-17 [68]. In an early phase II study, secukinumab provided a significant therapeutic response compared to placebo after 12 weeks, and is now in phase II and III studies [68].

IL-22 is another effector cytokine of Th17 cells that is crucial to the proliferation of keratinocytes, and the maintenance and remodeling of epithelial tissues $[69,70]$. Levels of IL-22 mRNA have been found to be upregulated in psoriatic skin lesions compared to normal skin, and, importantly, correlate to the severity of disease involvement and decrease with treatment efficacy $[70,71]$. Interestingly, intradermal injections of IL-23 in mouse models led to psoriasis-like skin changes while no such change was induced in IL-22 knockout mice, suggesting the essential role of IL-22 in psoriasis hyperkeratosis and making it an attractive therapeutic target [72].

\section{New Tumor Necrosis Factor Inhibitors}

TNF has been well documented to be involved in the immunopathology of psoriasis, and, in fact, is a well-known target for many of the currently approved biologic therapies for the treatment of psoriasis and psoriatic arthritis [73]. The efficacy and safety of several TNF inhibitors have been shown for adalimumab [74, 75], infliximab [76, 77], etanercept $[78,79]$, and golimumab [80]. Certolizumab pegol (CZP), a new TNF inhibitor with a completely different structure than the preceding anti-TNF biologic agents, is based on the pegylated Fab' portion of an anti-TNF antibody [81]. By omitting the antibody Fc fragment, this particular TNF inhibitor does not activate the complement cascade or antibody-dependent cellular toxicity [81]. CZP has already been shown to be useful in the treatment of other inflammatory diseases, including rheumatoid arthritis and Crohn's disease [82, 83]. A recent phase II randomized, placebo-controlled, double-blind study of 176 patients with moderate-to-severe plaque psoriasis used two different biweekly doses of CZP (200 mg and $400 \mathrm{mg}$ ) for a total treatment period of 12 weeks [84•]. At the end of 12 weeks, more patients receiving either $200 \mathrm{mg}$ or $400 \mathrm{mg}$ of CZP achieved a PASI 75 score compared to patients on placebo (74.6\% and $82.8 \%$ vs $6.8 \%$, respectively; $p<0.001$ ) [84•]. In addition, a greater proportion of CZP-treated patients on both doses improved to a Physician's Global Assessment (PGA) score of clear or almost clear compared to the 
placebo group $(52.5 \%$ and $72.4 \%$ vs $1.7 \%$; $p<0.001)$ [84•]. CZP provides an example of the utility of modifying treatments against already established targets for future drug development.

\section{T-cell Modulators}

Upstream to the cytokines that are targeted for the current and upcoming biologics are the $\mathrm{T}$ cells that are key to the immunopathology of psoriasis and psoriatic arthritis [73, 85]. Abatacept is a T-cell modulating biologic currently approved for the use in patients with rheumatoid arthritis and juvenile idiopathic arthritis [86, 87]. It is a soluble, fully human fusion protein comprised of the CTLA-4 domain that can bind CD80, or CD86 that was shown to improve psoriasis skin lesions in phase I studies and joint disease in a phase II trial [88, 89]. The recent phase II multicenter, randomized, double-blind, placebo-controlled study evaluated the efficacy and safety of three monthly doses (three doses of $3 \mathrm{mg} / \mathrm{kg}$, three doses of $10 \mathrm{mg} / \mathrm{kg}$, or two doses of $30 \mathrm{mg} / \mathrm{kg}$ followed by $10 \mathrm{mg} / \mathrm{kg}$ ) of abatacept in patients with psoriatic arthritis [89]. By day 169, a significant percentage of patients who received either the $10 \mathrm{mg} / \mathrm{kg}$ or the $30 / 10 \mathrm{mg} / \mathrm{kg}$ doses achieved an ACR 20 response compared to those patients on placebo ( $48 \%$ and $42 \%$ vs $19 \%$, respectively; $p<0.05$ ) [89].

Other notable T-cell modulators in development include a humanized IgG4k antibody against P-selectin glycoprotein ligand-1, which participates in the T-cell response during inflammation (AbGn-168; Boehringer Ingelheim, Ingelheim am Rhein, Germany) and a monoclonal antibody for CD4 (BT-061; Biotest, Dreieich, Germany), which functions as a co-receptor on CD4+ $\mathrm{T}$ helper cells $[90,91]$.

\section{Conclusion}

The initiation of the appropriate treatment and management strategy for psoriasis is vital to the prevention of disease progression and comorbidities, as well as significant financial expenses that can correlate with disease severity [92]. Although the spectrum of psoriasis treatment options has substantially increased and diversified, the average annual incremental indirect and direct costs is $\$ 1500$ per psoriasis patient per year [93]. Strikingly, a recent analysis of the costs of work loss and productivity, which are determinants of indirect costs, for psoriasis patients was estimated at $\$ 8.6$ and $\$ 9.9$ billion a year, respectively [94]. This calculation is a product of a multitude of factors, one of which may include those patients with inadequate treatment response, thereby making drug development and research an important factor to successful management of this chronic, debilitating condition.

Disclosure N. Kim: None; A.B. Gottlieb: investigator for Abbott Laboratories, Amgen, Celgene Corporation, Immune Control, Janssen Biotech, Novartis Pharmaceuticals, Novo Nordisk A/S, Pfizer, and UCB; consultant/advisory board member for Abbott Laboratories, Actelion, Amgen Astellas Pharma US, Beiersdorf, Bristol-Myers Squibb, Canfite, Celgene Corporation, Dermipsor, Incyte Corporation, Janssen Biotech, Lilly ICOS LLC, Merk \& Co., Novartis Pharmaceuticals, Novo Nordisk $\mathrm{A} / \mathrm{S}$, Pfizer, TEVA, and UCB; and research/educational grants from Abbott Laboratories, Amgen, Celgene Corporation, Janssen Biotech, Immune Control, Novartis Pharmaceuticals, Novo Nordisk A/S, Pfizer, and UCB.

\section{References}

Papers of particular interest, published recently, have been highlighted as:

- Of importance

1. Neimann AL, Porter SB, Gelfand JM. The epidemiology of psoriasis. Expert Rev Dermatol. 2006;1:63-75.

2. Gelfand JM, et al. Epidemiology of psoriatic arthritis in the population of the United States. J Am Acad Dermatol. 2005;53:573-7.

3. Taylor WJ. Epidemiology of psoriatic arthritis. Curr Opin Rheumatol. 2002;14:98-103.

4. Zachariae H. Prevalence of joint disease in patients with psoriasis: implications for therapy. Am J Clin Dermatol. 2003;4:441-7.

5. Neimann AL, et al. Prevalence of cardiovascular risk factors in patients with psoriasis. J Am Acad Dermatol. 2006;55:829-35.

6. Gelfand JM, et al. Risk of myocardial infarction in patients with psoriasis. JAMA. 2006;296:1735-41.

7. Cohen $\mathrm{AD}$, et al. Association between psoriasis and the metabolic syndrome. A cross-sectional study. Dermatology. 2008;216:152-5.

8. Han $\mathrm{C}$, et al. Increased prevalence of psychiatric disorders and health care-associated costs among patients with moderate-tosevere psoriasis. J Drugs Dermatol. 2011;10:843-50.

9. Sizto S, et al. Economic evaluation of systemic therapies for moderate to severe psoriasis. Br J Dermatol. 2009;160:1264-72.

10. Schmitt J, et al. Efficacy and tolerability of biologic and nonbiologic systemic treatments for moderate-to-severe psoriasis: metaanalysis of randomized controlled trials. Br J Dermatol. 2008;159:513-26.

11. Driessen RJB, et al. The economic impact of high-need psoriasis in daily clinical practice before and after the introduction of biologics. Br J Dermatol. 2010;162:1324-9.

12. Blauvelt A. New Concepts in the pathogenesis and treatment of psoriasis: key roles for IL-23, IL17A and TGF-beta1. Expert Rev Dermatol. 2007;2:1-10.

13. Di Cesare A, Di Meglio P, Nestle FO. The IL-23/Th17 axis in the immunopathogenesis of psoriasis. J Invest Dermatol. 2009;129: $1339-50$.

14. Wilson NJ, Boniface K, Chan JR, et al. Development, cytokine profile and function of human interleukin 17-producing helper $\mathrm{T}$ cells. Nat Immunol. 2007;8:950-7.

15. Manel N, Unutmaz D, Littman DR: The differentiation of human $T$ (H)-17 cells requires transforming growth factor-beta and induction of the nuclear receptor RORgammt. Nat Immunol, 9: 641-9 
16. Bettelli E, Carrier Y, Gao W, et al. Reciprocal developmental pathways for the generation of pathogenic effector TH17 and regulatory T cells. Nature. 2006;441:235-8.

17. Mangan PR, Harrington LE, O'Quinn DB, et al. Transforming growth factor-beta induces development of the $\mathrm{T}(\mathrm{H}) 17$ lineage. Nature. 2006;441:231-4.

18. Veldhoen M, Hocking RJ, Atkins CJ, et al. TGFbeta in the context of an inflammatory cytokine milieu supports de novo differentiation of IL-17-producing T cells. Immunity. 2006;24:179-89.

19. Flisiak I, Chodynicka B, Porebski P, Flisiak R. Association between psoriasis severity and transforming growth factor-beta1 and beta 2 in plasma and scales from psoriatic lesions. Cytokine. 2002;19:121-5.

20. Nickoloff BJ, Naidu Y. Perturbation of epidermal barrier function correlates with initiation of cytokine cascade in human skin. J Am Acad Dermatol. 1994;30:535-46.

21. Grossman RM, Krueger J, Yourish D, et al. Interleukin-6 (IL-6) is expressed in high levels in psoriatic skin and stimulates proliferation of cultured human keratinocytes. Proc Natl Acad Sci USA. 1989;86:6367-71.

22. Aggarwal S, Ghilardi N, XIe MH, de Sauvage FJ, Gurney AL. Interleukin-23 promotes a distinct $\mathrm{CD} 4 \mathrm{~T}$ cell activation state characterized by the production of interleukin-17. J BIol Chem. 2003;278:1910-4.

23. Langrish CL, Chen Y, Blumenschein WM, et al. IL-23 drives a pathogenic $\mathrm{T}$ cell population that induces autoimmune inflammation. J Exp Med. 2005;201:233-40.

24. Stockinger B, Veldhoen M. Differentiation and function of Th17 T cells. Curr Opin Immuno. 2007;19:281-6.

25. Oppmann B, Lesley R, Blom B, et al. Novel p19 protein engages IL-12p40 to form a cytokine, IL-23, with biological activities similar as well as distinct from IL-12. Immunity. 2000;13:715-25.

26. Piskin G, Sylva-Steenland RM, Bos JD, Teunissen MB. In vitro and in situ expression of IL-23 by keratinocytes in health skin and psoriasis lesions: enhanced expression in psoriatic skin. J Immunol. 2006;176:1908-15.

27. Parham C, Chirica M, Timans J, et al. A receptor for the heterodimeric cytokine IL-23 is composed of IL-12beta1 and a novel cytokine receptor subunit, IL-23R. J Immunol. 2002;168:5699-708.

28. Robertson MJ, Ritz J. Interleukin 12: basic biology and potential applications in cancer treatment. Oncologist. 1996;1:88-97.

29. Chan JR, Blumenschein W, Murphy E, et al. IL-23 stimulates epidermal hyperplasia via TNF and IL-20R2-dependent mechanisms with implications for psoriasis pathogenesis. J Exp Med. 2006;203:2577-87.

30. Toichi E, Torres G, McCormick TS, et al. An anti-IL-12p40 antibody down-regulates type 1 cytokines, chemokines, and IL12/IL-23 in psoriasis. J Immunol. 2006;177:4917-26.

31. Lee E, Trepicchio WL, Oestreicher JL, et al. Increased expression of interleukin 23 p19 and p40 in lesional skin of patients with psoriasis vulgaris. J Exp Med. 2004;199:125-30.

32. Haider AS, Lowes MA, Suarez-Farinas M, et al. Identification of cellular pathways of "type I", Th17 T cells, and TNF- and inducible nitric oxide synthase-producing dendritic cells in autoimmune inflammation through pharmacogenomic study of cyclosporine A in psoriasis. J Immunol. 2008;180:1913-20.

33. Gottlieb AB, Chamian F, Masud S, et al. TNF inhibition rapidly down-regulates multiple proinflammatory pathways in psoriasis plaques. J Immunol. 2005;175:2721-9.

34. Piskin G, Tursen U, Sylva-Steenland RM, Bos JD, Teunissen MB. Clinical improvement in chronic plaque-type psoriasis lesions after narrow-band UVB therapy is accompanied by a decrease in the expression of IFN-gamma inducers- IL-12, IL-18 and IL-23. Exp Dermatol. 2004;13:764-72.

35. Cargill M, Schrodi SJ, Chang M, et al. A large-scale genetic association study confirms IL12B and leads to the identification of IL23R as psoriasis-risk genes. Am J Hum Genet. 2007;80: 273-90.

36. Capon F, Di Meglio P, Szaub J, et al. Sequence variants in the genes for the interleukin-23 receptor (IL23R) and its ligand (IL12B) confer protection against psoriasis. Hum Genet. 2007;122:201-6.

37. Nair RP, Ruether A, Stuart PE, et al. Polymorphisms of the IL12B and IL23R genes are associated with psoriasis. J Invest Dermatol. 2008;128:1653-61.

38. Luo J, Wu SJ, Lacy ER, et al. Structural basis for the dual recognition of IL-12 and IL-23 by ustekinumab. J Mol Biol. 2010;402:797-812.

39. Kaufmann CL, Aria N, Toichi E, et al. A phase I study evaluating the safety, pharmacokinetics, and clinical response of a human IL12 p40 antibody in subjects with plaque psoriasis. J Invest Dermatol. $2004 ; 123: 1037-44$.

40. Gottlieb AB, Copper KD, McCormick TS, et al. A phase I, doubleblind, placebo-controlled study evaluating single subcutaneous administration of human interleukin-12/23 monoclonal antibody in subjects with plaque psoriasis. Curr Med Res Opin. 2007;23:1081-92.

41. Krueger GG, Langely RG, Leonardi C, et al. A human Interleukin $12 / 23$ monoclonal antibody for the treatment of psoriasis. N Eng J Med. 2007;356:580-92.

42. - Leonardi CL, Kimball AB, Papp KA, et al. Efficacy and safety of Ustekinumab, a human interleukin 12/23 monoclonal antibody, in patients with psoriasis: 76-week results from a randomized, double blind, placebo-controlled trial (PHOENIX 1). Lancet. 2008;371:1665-74. This paper discusses and evaluates the results of a phase III, randomized, double-blind, placebo-controlled clinical trial on the efficacy and safety of ustekinumab in psoriasis treatment.

43. - Papp KA, Langely RG, Lebwohl M, et al. Efficacy and safety of ustekinumab, a human interleukin 12/23 monoclonal antibody, in patients with psoriasis: 52-week results from a randomized, double blind, placebo-controlled trial (PHOENIX 2). Lancet. 2008;371:1675-84. This paper discusses and evaluates the results of a phase III, randomized, double-blind, placebo-controlled clinical trial on the efficacy and safety of ustekinumab in psoriasis treatment.

44. - Griffiths CEM, Strober B, van de Kerkhof PCM, et al: A phase 3 multicenter, randomized study comparing ustekinumab and etanercept for the treatment of moderate to severe plaque psoriasis. European Academy of Dermatology and Venerology Annual Congress Paris 2008, FP1336. This paper discusses and evaluates the results of a phase III, randomized comparator clinical study between ustekinumab and etanercept for the treatment of moderateto-severe psoriasis.

45. - Gottlieb A, Menter A, Mendelsohn A, et al. Ustekinumab, a human interleukin 12/23 antibody, for psoriatic arthritis: randomized, double-blind, placebo-controlled, crossover trial. Lancet. 2009;373:633-40. This paper discusses and evaluates the results of a phase III, randomized, double-blind, placebo-controlled clinical trial on the efficacy and safety of ustekinumab for the treatment of psoriatic arthritis.

46. U.S. National Institutes of Health: ClinicalTrials.gov. Available from: http://www.Clinicaltrials.Gov/ct2/results?Term=psoriasis. Accessed May 2012.

47. • Au SC, Goldminz AM, Kim N, et al. Investigator-initiated, openlabel trial of ustekinumab for the treatment of moderate-to-severe palmoplantar psoriasis. J Dermatolog Treat. 2012. doi:10.3109/ 09546634.2012.672710. This paper discusses the results of the open-label trial of ustekinumab for the treatment of palmoplantar psoriasis.

48. Kimball AB, Gordon KB, Langely RG, et al. Safety and efficacy of ABT-874, a fully human interleukin $12 / 23$ monoclonal antibody in 
the treatment of moderate to severe chronic plaque psoriasis. Arch Dermatol. 2008;144:200-7.

49. Ding C, Xu J, Li J. ABT-874, a fully human monoclonal anti-IL12/IL-23 antibody for the potential treatment of autoimmune diseases. Curr Opin Investig Drugs. 2008;9:515-22.

50. - Gordon KB, Langely RG, Gottlieb AB, et al. A phase iii, randomized, controlled trial of the fully human i1-12/23 mab briakinumab in moderate-to-severe psoriasis. J Invest Dermatol. 2012;132:304-14. This paper discusses and evaluates the results of a phase III, randomized, controlled clinical study on the efficacy and safety of briakinumab in psoriasis treatment.

51. • Reich K, Langley RG, Papp KA, et al. A 52-week trial comparing briakinumab with methotrexate in patients with psoriasis. N Engl $\mathrm{J}$ Med. 2011;365:1586-96. Discusses the results of a randomized, comparator study between briakinumab and methotrexate for the treatment of psoriasis.

52. - Gottlieb AB, Leonardi C, Kerdel F, et al. Efficacy and safety of briakinumab versus etanercept and placebo in patients with moderate to severe chronic plaque psoriasis. Br J Dermatol. 2011;165:652-60. This paper discusses and evaluates the results of a phase III, randomized, placebo-controlled comparator trial between briakinumab and etanercept for the treatment of moderate-to-severe psoriasis.

53. Ryan C, Leonardi CL, Kreuger JG, et al. Association between biologic therapies for chronic plaque psoriasis and cardiovascular events: a meta-analysis of randomized controlled trials. JAMA. 2011;306:864-71.

54. Nakajima K, Kanda T, Takaishi M, et al. Disinct role of IL-23 and IL-17 in the development of psoriasis-like lesions in a mouse model. J Immunol. 2011;186:4481-9.

55. O'Neill JL, Kalb RE. Ustekinumab in the therapy of chronic plaque psoriasis. Biologics. 2009;3:159-68.

56. Fitch E, Harper E, Skorcheva I, Kurtz SE, Blauvelt A. Pathophysiology of psoriasis: recent advances on IL-23 and Th17 cytokines. Curr Rheumatol Rep. 2007;9:461-7.

57. Dong C. Diversification of T-helper-cell lineages: finding the family root of IL-17-producing cells. Nat Rev Immunol. 2006;6:329-33.

58. Shalom-Barak T, Quach J, Lotz M. Interleukin-17-induced gene expression in articular chondrocytes is associated with activation of mitogen-activated protein kinases and NF-kappaB. J Biol Chem. 1998;273:27467-73.

59. Laan M, Cui ZH, Hoshino $\mathrm{H}$, et al. Neutrophil recruitment by human IL-17 via C-X-C chemokine release in the airways. J Immunol. 1999;162:2347-52.

60. Starnes T, Broxmeyer HE, Robertson MJ, Hromas R. Cutting edge: IL17 D, a novel member of the IL-17 family, stimulates cytokine production and inhibits hemopoiesis. J Immunol. 2002;169:642-6.

61. Dragon S, Saffar AS, Shan L, Gounni AS. IL-17 attenuates the anti-apoptotic effects of GM-CSF in human neutrophils. Mol Immunol. 2008;45:160-8.

62. Ruddy MJ, Wong GC, Liu XK, et al. Functional cooperation between interleukin-17 and tumor necrosis factor-alpha is mediated by CCAAT/enhancer-binding protein family members. J Biol Chem. 2004;279:2559-67.

63. Yao Z, Painter SL, Fanslow WC, et al. Human IL-17: a novel cytokine derived from T cells. J Immunol. 1995;155:5483-6.

64. Russell C, Kerkof K, Bigler J, et al. Blockade of the IL-17R with AMG 827 leads to rapid reversal of gene expression and histopathologic abnormalities in psoriatic skin, including substantial pathway-specific effects within one week. J Invest Dermatol. 2011;131:S11

65. Russell C, Kerkof K, Bigler J, et al. Blockade of the IL-17R with AMG 827 leads to rapid reversal of gene expression and histopathologic abnormalities in human psoriatic skin. J Invest Dermatol. 2010;130:S46.
66. - Papp KA, Leonardi C, Menter A, et al. Brodalumab, an antiinterleukin-17-receptor antibody for psoriasis. N Engl J Med. 2012;366:1181-9. This paper discusses and evaluates the results of a phase II, randomized, double-blind, placebo-controlled trial on the efficacy and safety of brodalumab, an IL-17 inhibitor, in psoriasis treatment.

67. - Leonardi C, Matheson R, Zachariae C, et al. Anti-interleukin-17 monoclonal antibody ixekizumab in chronic plaque psoriasis. $\mathrm{N}$ Engl J Med. 2012;366:1190-9. This paper discusses and evaluates the results of a phase II, randomized, double blind, placebocontrolled trial on the efficacy and safety of ixekizumab, an IL17 inhibitor, in psoriasis treatment.

68. Hueber W, Patel D, Dryja T, et al. Effects of AIN457, a fully human antibody to interleukin-17A, on psoriasis, rheumatoid arthritis, and uveitis. Sci Transl Med. 2010;2:52ra72.

69. Boniface K, Bernard FX, Garcia M, et al. IL-22 inhibits epidermal differentiation and induces proinflammatory gene expression and migration of human keratinocytes. J Immunol. 2005;174:3695-702.

70. Wolk K, Witte E, Wallace E, et al. IL-22 regulates the expression of genes responsible for antimicrobial defense, cellular differentiation, and mobility in keratinocytes: a potential role in psoriasis. Eur J Immunol. 2006;36:1309-23.

71. Boniface K, Guignouard E, Pedretti N, et al. A role for T cellderived interleukin 22 in psoriatic skin inflammation. Clin Exp Immunol. 2007;150:407-15.

72. Zhang Y, Danilenko DM, Valdez P, et al. Interleukin-22, a T(H) 17 cytokine, mediates IL-23-induced dermal inflammation and acanthosis. Nature. 2007;445:648-51.

73. Gaspari AA. Innate and adaptive immunity and the pathophysiology of psoriasis. J Am Acad Dermatol. 2006;54:S67-80.

74. Gordon K. Efficacy and safety of adalimumab treatment in patients with moderate to severe psoriasis: a double-blind, randomized clinical trial. Psoriasis Forum. 2007;13:4-11.

75. Mease PJ, Gladman DD, Ritchlin CT, et al. Adalimumab for the treatment of patients with moderately to severely active psoriatic arthritis: results of a double-blind, randomized, placebo-controlled trial. Arthritis Rheum. 2005;52:279-89.

76. Chaudhari U, Romano P, Mulcahy LD, et al. Efficacy and safety of infliximab monotherapy for plaque-type psoriasis: a randomized trial. Lancet. 2001;357:1842-7.

77. Antoni C, Krueger GG, de Vlam K, et al. Infliximab improves signs and symptoms of psoriatic arthritis: results of the IMPACT 2 trial. Ann Rheum Dis. 2005;64:1150-7.

78. Papp KA, Tyring S, Lahfa M, et al. A global phase III randomized controlled trial of etanercept in psoriasis: safety, efficacy, and effect of dose reduction. Br J Dermatol. 2005;152:1304-12.

79. Mease PJ, Kivitz AJ, Burch FX, et al. Etanercept treatment of psoriatic arthritis: safety, efficacy, and effect on disease progression. Arthritis Rheum. 2004;50:2264-72.

80. Kavanaugh A, McInnes I, Mease P, et al. Golimumab, a new human tumor necrosis factor $\alpha$ antibody, administered every four weeks as a subcutaneous injection in psoriatic arthritis. Arthritis Rheum. 2009;60:976-86.

81. Nesbitt A, Fossati G, Bergin M, et al. Mechanism of action of certolizumab pegol (CDP870): in vitro comparison with other antitumor necrosis factor alpha agents. Inflamm Bowel Dis. 2007; 13:1323-32.

82. Fleischmann R, Vencovsky J, van Vollenhoven RF, et al. Efficacy and safety of certolizumab pegol monotherapy every 4 weeks in patients with rheumatoid arthritis failing previous diseasemodifying antirheumatic therapy: the FAST4WARD study. Ann Rheum Dis. 2009;68:805-11.

83. Sandborn WJ, Feagan BG, Stoinov S, et al. Certolizumab pegol for the treatment of Crohn's disease. N Engl J Med. 2007;357:228-38.

84. - Reich K, Ortonne JP, Gottlieb AB, et al. Successful treatment of moderate to severe plaque psoriasis with the PEGylated Fab' 
certolizumab pegol: results of a phase II randomized, placebocontrolled trial with a re-treatment extension. BJD. 2012. doi:10.1111/j.1365-2133.2012.10941.x. This paper discusses and evaluates the results of a phase II, randomized, placebocontrolled study on the efficacy and safety of CZP for the treatment of psoriasis.

85. Choy E. T cells in psoriatic arthritis. Curr Rheumatol Rep. 2007;9:437-41.

86. Genovese MC, Becker JC, Schiff M, et al. Abatacept for rheumatoid arthritis refractory to tumor necrosis factor inhibition. N Engl J Med. 2005;11:1114-23.

87. Ruperto N, Lovell DJ, Quartier P, et al. Abatacept in children with juvenile idiopathic arthritis: a randomized, double-blind, placebocontrolled withdrawal trial. Lancet. 2008;372:383-91.

88. Abrams JR, Lebwohl MG, Guzzo CA, et al. CTLA4Ig-mediated blockage of $\mathrm{T}$ cell costimulation in patients with psoriasis vulgaris. J Clin Invest. 1999;103:1243-52.
89. Mease P, Genovese MC, Gladstein G, et al. Abatacept in the treatment of patients with psoriatic arthritis. Arthritis Rheum. 2011;63:939-48.

90. Rossi B, Constantin G. Anti-selectin therapy for the treatment of inflammatory diseases. Inflamm Allergy Drug Targets. 2008;7:85-93.

91. Piccirillo CA, d'Hennezel E, Sgouroudis E, Yurchenko E. Cd4+ foxp 3 +regulatory $t$ cells in the control of autoimmunity: in vivo veritas. Curr Opin Immunol. 2008;20:655-62.

92. Feldman SR, Fleischer Jr AB, Reboussin DM, et al. The economic impact of psoriasis increases with psoriasis severity. J Am Acad Dermatol. 1997;37:564-9.

93. Fowler JF, Duh MS, Rovba L, et al. The impact of psoriasis on health care costs and patient work loss. J Am Acad Dermatol. 2008;59:772-80.

94. Schmitt JM, Ford DE. Work limitations and productivity loss are associated with health-related quality of life but not with clinical severity in patients with psoriasis. Dermatology. 2006;213:102-10. 